\title{
Physical disease in schizophrenia: a population-based analysis in Spain
}

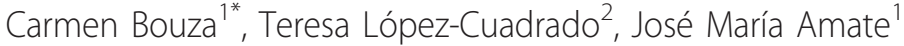

\begin{abstract}
Background: Physical disease remains a challenge in patients with schizophrenia. Our objective was to determine the epidemiological characteristics and burden of physical disease in hospitalized patients with schizophrenia.

Methods: We analyzed the 2004 Spanish National Hospital Discharge Registry, identified records coded for schizophrenia (295.xx) and characterized the physical diseases using the ICD-9 system and the Charlson Index. We also calculated standardized mortality ratios (SMRs) versus the general population adjusted by age and calendar time.

Results: A total of 16, 776 cases (mean age: 43 years, 65\% males) were considered for analysis. Overall, $61 \%$ of cases had at least one ICD-9 physical code and 32\% had more than one ICD-9 code. The Charlson index indicated that $20 \%$ of cases had a physical disease of known clinical impact and prognostic significance. Physical disease appeared early in life (50\% of cases were 15-31 years of age) and increased rapidly in incidence with age. Thus, for patients aged 53 years or more, $84 \%$ had at least one physical ICD-9 code. Apart from substance abuse and addiction, the most prevalent diseases were endocrine (16\%), circulatory (15\%), respiratory (15\%), injury-poisoning (11\%), and digestive (10\%). There were gender-related differences in disease burden and type of disease. In-hospital mortality significantly correlated with age, the Charlson Index and several ICD-9 groups of physical disease. Physical disease was associated with an overall 3.6-fold increase in SMRs compared with the general population.

Conclusions: This study provides the first nationally representative estimate of the prevalence and characteristics of physical disease in hospitalized patients with schizophrenia in Spain. Our results indicate that schizophrenia is associated with a substantial burden of physical comorbidities; that these comorbidities appear early in life; and that they have a substantial impact on mortality. This information raises concerns about the consequences and causes of physical disorders in patients with schizophrenia. Additionally, it will help to guide the design and implementation of preventive and therapeutic programs from the viewpoint of clinical care and in terms of healthcare service planning.
\end{abstract}

\section{Background}

There is growing interest in the effects of physical disease on patients with schizophrenia. Physical disease can affect psychiatric signs and symptoms, response to psychoactive drugs, life expectancy, and use of healthcare services [1-5]. However, there is no consensus about how to treat or prevent physical disease in patients with schizophrenia [6,7]. This is mainly because of the difficulties involved in selecting and analyzing representative samples of such patients [8].

\footnotetext{
* Correspondence: cbouza@isciii.es

'Health-Care Technology Assessment Agency, Instituto de Salud Carlos III, Madrid, Spain

Full list of author information is available at the end of the article
}

In Spain, following psychiatric reform and the deinstitutionalization process in the $1980 \mathrm{~s}$, most people with schizophrenia live in the community and receive public universal healthcare in the same centers used by the general population [9-11]. In this scenario, our hypothesis is that the study of physical disease in hospitalized people with schizophrenia may provide relevant information for clinical practice and healthcare planning.

The objective of the present study was to examine physical disease in hospitalized people with schizophrenia, describe the epidemiological characteristics, and identify the most prevalent physical diseases as well as their impact on mortality by analysis of a national administrative database.

\section{Biomed Central}




\section{Methods}

This study used the National Hospital Discharge Registry of Spain, the official database of the Ministry of Health [12]. This information is derived from discharge reports from all acute-care hospitals, and is representative of the national population, as it includes data on over $90 \%$ of all annual hospital admissions nationwide.

The registry, mandated by law, includes demographic data; clinical data, including diagnoses (one main or primary diagnosis and up to 12 additional diagnoses all of which are considered as secondary diagnoses) coded according to the International Classification of Diseases, $9^{\text {th }}$ Revision, Clinical Modification (ICD-9-CM); dates of admission and discharge; type of admission; and characteristics and disposition upon hospital discharge.

We used population figures from the 2003-04 National Health Survey [13] to compare physical-disease prevalence between our study population and the general population. We also obtained demographic national population data from the National Statistics Institute [13].

\section{Period of analysis}

We used data from the national database that covered the period January 1 to December 31, 2004.

\section{Case selection}

Cases were selected by identification of codes corresponding to schizophrenia (ICD-9 codes 295.xx), among hospitalized subjects aged $\geq 15$ years. Afterward, to avoid an overestimation of comorbidities and outcomes for each case, we performed a process of filtering and depuration of the database in which we explored the number of hospital discharges in the analysis period. To carry this out, the following identification variables were chosen: birth date, gender, admission date, discharge date, postal code and readmission (coded as a binary variable). In the database refinement process used in this study, 1,776 cases were identified, within the analysis period, as having been readmitted into the same hospital and with the same main diagnosis. Subsequently, among the admissions identified for each patient, the most complete one, in terms of coding with respect to the coding for the main diagnosis and the secondary ones, was chosen.

\section{Comorbidities}

For each case, physical disease was characterized by ICD-9 codes: infectious diseases (001-139); neoplasms (140-239); endocrine diseases (240-279); hematological diseases (280-289); neurological diseases (320-389); diseases of the circulatory system (390-459); respiratory diseases (460-519); diseases of the digestive system
(520-579); diseases of the genitourinary tract (580-629); complications of pregnancy, childbirth, and the puerperium (630-677); diseases of the skin and subcutaneous tissue (680-709); diseases of the musculoskeletal system and connective tissue (713-739); and injury and poisoning (800-999). Within each category of physical illnesses, those considered of special clinical relevance, such as Chronic Obstructive Pulmonary Disease (COPD); Ischemic Heart Disease (IHD); Myocardial Infarction (MI) and Diabetes will be analyzed specifically.

In addition, specific codes were used to identify abuse or dependency on drugs (codes ICD-9: 304.8, 304.2, 305.9), alcohol (305.0, 303.9), and tobacco (305.1, 989.84, E869.4) given their known capacity for generating or complicating the course of physical disease in patients with schizophrenia [14]. Finally, to determine the extent of physical comorbidities of known prognostic value, we used a validated ICD-9 version [15] of the Charlson comorbidity index [16]. In accordance with prior literature [17], four different score groups (0, 1-2, $3-4,>4$ ) were employed.

\section{Ethical issues}

The study was exempt from institutional review board approval, because only de-identified administrative data were used.

\section{Data analysis}

This descriptive study analyzed the prevalence (and 95\% CIs) of selected physical morbidities and their distribution according to gender and age quartiles. Data are summarized as frequencies and percentages for categorical variables. Continuous variables are presented as means and standard deviations (SD). For between-group comparisons, we used $\chi^{2}$ tests for categorical data. Continuous variables were analyzed with Snedecor's F test or the Mann-Whitney U test. Odds ratios (ORs) with 95\% confidence intervals were computed where appropriate. We used an exploratory logistic regression analysis to identify the impact of physical illness upon in-hospital mortality.

The age-and gender-standardized rates were calculated by direct standardization based on the 2004 Spanish population aged $\geq 15$ years [18].

We estimated expected values for mortality by 10 years-age groups based on the 2004 Spanish population aged $\geq 15$ years. Observed and expected numbers of deaths were used to calculate the standardized mortality ratios (SMRs) versus the general population [2]. In order to explore the impact of physical disease on the risk of death, SMRs were calculated for the subgroups of cases with/without ICD-9 codes of physical disease. 
All analyses were performed with SPSS version 15.0 for Windows (SPSS Inc., Chicago, IL). A p-value $<0.05$ was considered significant.

\section{Results}

Of the 3,951,214 hospital discharges registered in subjects $\geq 15$ years of age across the nation in 2004, and after carrying out several depuration processes for the database, 16776 records with schizophrenia were eligible for analysis (incidence rate 46.23 cases per 100,000 population/year). Of the total number of cases, $64 \%$ of hospitalisations $(\mathrm{n}=10745 ; 29.6$ cases per 100,000 population/year) appeared to be directly associated with schizophrenia, inasmuch as schizophrenia is shown as the principal diagnosis, whereas in the remaining $36 \%$ ( $\mathrm{n}=6031 ; 16.63$ cases per 100,000 population/year), the primary cause of hospitalisation was stated to be some other disease.
Stratification by age-groups is shown in Figure 1 .

As shown in Table 1 hospital admissions were mostly for acute conditions through emergency departments and more frequent in men. Mean age of the cases was 43 years and men were significantly younger than women $(41.2 \pm 14.7$ years vs. $47.9 \pm 17$ years; $\mathrm{p}<0.001)$.

The mean number of physical ICD-9 codes was $1.22 \pm$ 1.38 (range 0-8), and women had significantly more codes than men $(1.26 \pm 1.4$ vs. $1.20 \pm 1.3 ; \mathrm{p}=0.002)$. Overall, $61 \%$ of patients had at least one ICD-9 code, and $32 \%$ had more than one ICD-9 code. Stratification by age showed that $50 \%$ of cases were younger subjects (15-31 years of age), and that the number of ICD-9 codes increased with age. Thus, for patients aged 53 years or more, $84 \%$ had at least one physical ICD-9 code $(17 \%$ had one code; $24 \%$ two codes; and $43 \%$ three or more codes). This increase with age occurred for both men and women.

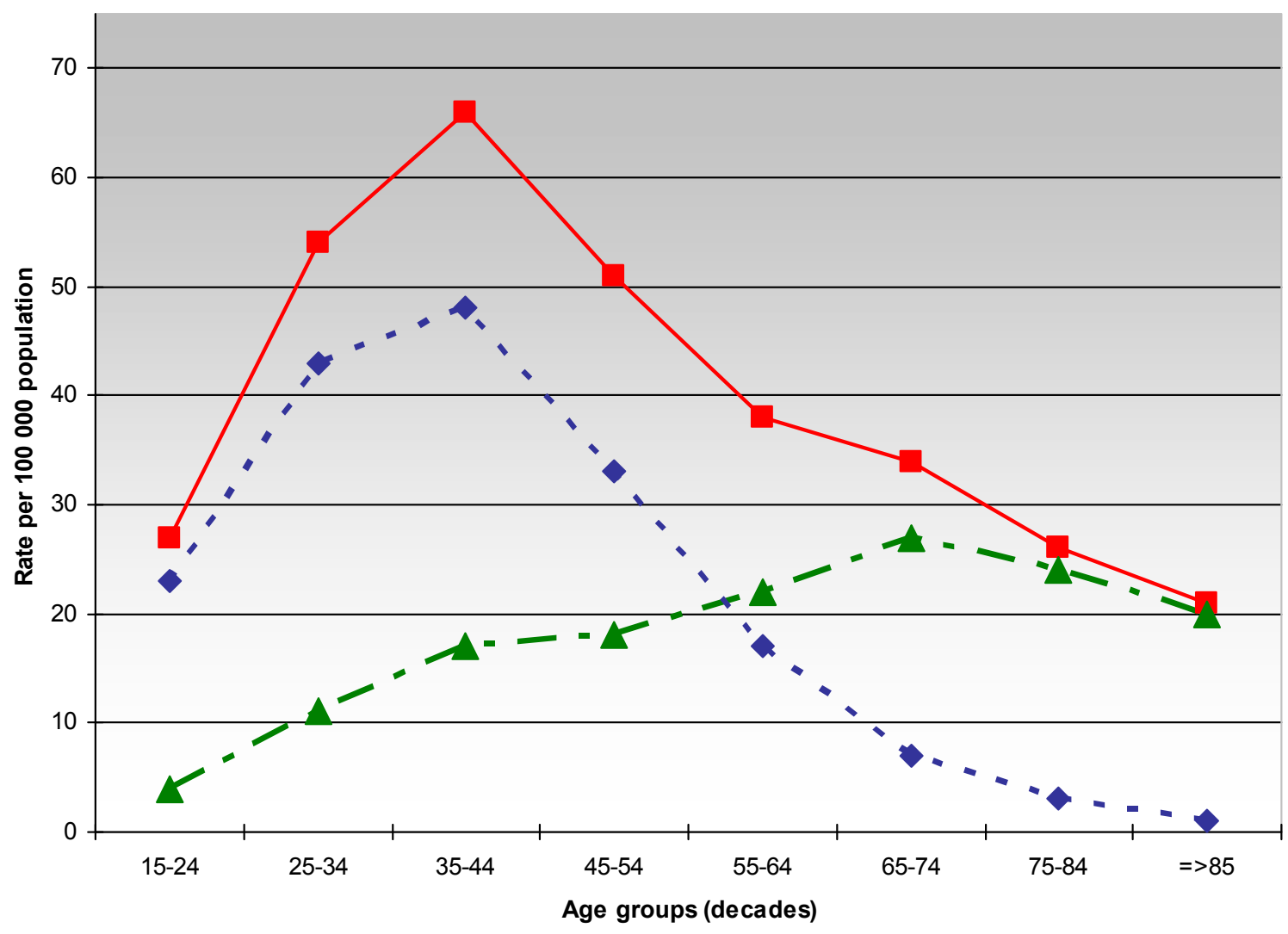

Figure 1 Hospital admissions in patients with schizophrenia. Rates of hospitalizations in patients with schizophrenia in Spain according to 10-year age groups and principal diagnosis at discharge. Overall rate (filled squares/solid line), data for cases with principal diagnosis of schizophrenia (filled diamonds/dotted line), data for cases admitted due to physical disease (filled triangles/dotted line). 
Table 1 Global characteristics of the population

\begin{tabular}{|c|c|c|c|}
\hline & Total & Men & Women \\
\hline Cases & 16776 & $10952(65 \%)$ & $5818(35 \%)$ \\
\hline \multicolumn{4}{|l|}{ Hospital admission: } \\
\hline Acute & $14699(88 \%)$ & $9625(88 \%)$ & $5069(87 \%)$ \\
\hline Scheduled & $2066(12 \%)$ & $1320(12 \%)$ & $745(13 \%)$ \\
\hline Schizophrenia in principal diagnosis at hospital discharge & $10745(64 \%)$ & $7209(66 \%)$ & $3532(61 \%)$ \\
\hline Age, years & $43.5 \pm 16$ & $41.2 \pm 14.8$ & $47.9 \pm 17.2$ \\
\hline \multicolumn{4}{|l|}{ Age, decades } \\
\hline $15-24$ years & $1483(8.8 \%)$ & $1149(10.5 \%)$ & $333(5.7 \%)$ \\
\hline 25-34 years & $4054(24,2 \%)$ & $2938(26.8 \%)$ & $1114(19.1 \%)$ \\
\hline $35-44$ years & 4560 (27.2\%) & $3122(28.5 \%)$ & $1437(14.7 \%)$ \\
\hline $45-54$ years & $2784(16.6 \%)$ & $1754(16 \%)$ & $1030(17.7 \%)$ \\
\hline $55-64$ years & 1699 (10.1\%) & $963(8.8 \%)$ & $735(12.6 \%)$ \\
\hline $65-74$ years & $1350(8 \%)$ & $718(6.6 \%)$ & $632(10.9 \%)$ \\
\hline $75-84$ years & $680(4.1 \%)$ & $270(2.5 \%)$ & $409(7 \%)$ \\
\hline$\geq 85$ years & $166(0.99 \%)$ & $38(0.3 \%)$ & $128(2.2 \%)$ \\
\hline Mean ICD-9-CM codes & $1.22 \pm 1.38$ & $1.20 \pm 1.34$ & $1.26 \pm 1.46$ \\
\hline \multicolumn{4}{|l|}{ Number of codes: } \\
\hline 1 & $4914(29 \%)$ & $3482(31.8 \%)$ & $1430(24.6 \%)$ \\
\hline 2 & $2549(15 \%)$ & $1660(15.2 \%)$ & $889(15.3 \%)$ \\
\hline 3 & $1451(9 \%)$ & $879(8.0 \%)$ & $571(9.8 \%)$ \\
\hline 4 & $771(5 \%)$ & $461(4.2 \%)$ & $310(5.3 \%)$ \\
\hline$\geq 5$ & $548(3.3 \%)$ & $330(3.1 \%)$ & $218(3.8 \%)$ \\
\hline Mean Charlson Index & $0.43 \pm 1.26$ & $0.43 \pm 1.28$ & $0.43 \pm 1.20$ \\
\hline \multicolumn{4}{|l|}{ Charlson Index (categorized) } \\
\hline 0 points & $13518(81 \%)$ & $8912(81.4 \%)$ & $4602(79.1 \%)$ \\
\hline 1,2 points & $2559(15 \%)$ & $1561(14.3 \%)$ & $996(17.1 \%)$ \\
\hline 3,4 points & $274(2 \%)$ & $183(1.7 \%)$ & $91(1.6 \%)$ \\
\hline$>4$ points & $425(2.5 \%)$ & $296(2.7 \%)$ & $129(2.2 \%)$ \\
\hline
\end{tabular}

Data are shown as mean \pm standard deviation or number of cases and percentages (\%)

The differences between the some of the gender data and the total population are due to missing values.

Furthermore, 20\% of the cases had Charlson indices greater than zero, although there was no statistically significant difference between the genders. The severity of this index rose significantly with age, independent of gender.

Addiction to drugs, alcohol, or tobacco was the most significant problem, and about one-third of cases had a code indicating substance abuse or dependency (Table 2). With respect to defined ICD-9 groups, the most frequent were endocrine problems, circulatory and respiratory diseases, and injury-poisoning. Within these categories, diabetes mellitus and chronic obstructive pulmonary disease (COPD) were pre-eminent, with an overall prevalence of $8 \%$ and $5.5 \%$, respectively. Ischemic heart disease was present in 338 cases: of these, 185 had myocardial infarction, corresponding to an overall prevalence of $1.1 \%$ (95\% CI: 0.94-1.26).

The number of cases in all ICD-9 groups increased with age. In the case of endocrine and circulatory diseases, almost $40 \%$ of the population over the age of 53 was affected. In addition, there were gender-related differences in the prevalence of several ICD-9 groups (Table 3).

Approximately $13 \%$ of cases $(\mathrm{n}=2,210)$ underwent surgical procedures during hospitalization, where digestive $(\mathrm{n}=349)$ and musculoskeletal $(\mathrm{n}=351)$ procedures were the most common.

A comparison between our data and the official data for the Spanish population provided by the National Health Survey [13] indicate that diabetes rates are clearly higher, twice as high in the case of women, than those observed for the general Spanish population (5.02\% overall, $5.29 \%$ in women and $4.73 \%$ in men). The frequency of neoplasms observed in our study is also higher than that reported in the population data for Spain $(2.37 \%$ overall, $1.92 \%$ in men and $2.79 \%$ in women). Similarly, our cases register a higher rate of tobacco and alcohol abuse/dependence than does the 
Table 2 Frequency of specific ICD-9 physical diseases

\begin{tabular}{|c|c|}
\hline ICD-9-CM groups & No. cases, $\%$ and $(95 \% \mathrm{Cl})$ \\
\hline Substance abuse/dependency & $4899,29(28.5-29.9)$ \\
\hline Tobacco & $2533,15(13.6-16.4)$ \\
\hline Alcohol & $1745,10.4(9.9-10.9)$ \\
\hline Drugs & $2377,14.2(13.6-14.7)$ \\
\hline Endocrine, nutritional and metabolic diseases & $2772,16.5 \%(15.9-17.1)$ \\
\hline Diabetes & $1339,8 \%(6.54-9.44)$ \\
\hline Diseases of the Circulatory System & $2458,14.7 \%(14-15.2)$ \\
\hline Ischemic heart disease & $338,2 \%(0.55-3.6)$ \\
\hline Cardiac failure & $260,1.5 \%(1.36-1.74)$ \\
\hline Cerebrovascular Disease & $257,1.5 \%(1.35-1.72)$ \\
\hline Diseases of the Respiratory System & $2056,12.3 \%(11.8-12.8)$ \\
\hline COPD & $926,5.5 \%(5.17-5.87)$ \\
\hline Injury-Poisoning & $1901,11.3 \%(9.89-12.73)$ \\
\hline Diseases of the Digestive System & $1749,10.4 \%(9.96-10.9)$ \\
\hline Hepatic & $57,0.3 \%(0.25-0.43)$ \\
\hline Diseases of the Nervous System & $1401,8.4 \%(7.9-8.8)$ \\
\hline Dementia & $130,0.8 \%(0.64-0.91)$ \\
\hline Diseases of the Genitourinary System & $1168,7 \%(6.6-7.4)$ \\
\hline Renal Insufficiency & $172,1 \%(0.87-1.18)$ \\
\hline Infectious and parasitic diseases & $1095,6.5 \%(6.2-6.9)$ \\
\hline AIDS & $190,1.1 \%(0.97-1.29)$ \\
\hline Neoplasms & $746,4.4 \%(4.1-4.8)$ \\
\hline Diseases of the Blood and blood-forming organs & $724,4.3 \%(4.0-4.3)$ \\
\hline Diseases of the Skin and Subcutaneous Tissue & $540,3.2 \%(2.9-3.5)$ \\
\hline Diseases of the Musculoskeletal \& Connective Tissue & $552,3.3 \%(3.0-3.6)$ \\
\hline Complications of pregnancy, childbirth and the puerperium & $113,1.94 \%(1.6-2.3)$ \\
\hline
\end{tabular}

general Spanish population with $12.8 \%$ and $2.55 \%$ of the population (4.5\% of men and $0.6 \%$ of women) being classified as heavy smokers and excessive drinkers respectively, and also a high rate of AIDS (1.61 per 1000 population). On the other hand, we found no pronounced differences in the frequency of COPD (5.33\% in the overall Spanish population) and ischemic heart disease $(2.39 \%$ overall, $3.2 \%$ in men and $1.62 \%$ in women).

Regarding outcomes, $88 \%$ of the cases $(\mathrm{n}=14,701)$ returned home; $6.2 \%(\mathrm{n}=1,036)$ were transferred to other hospitals; $2.1 \%(\mathrm{n}=356)$ were transferred to a socio-health care center; and $2.3 \%(\mathrm{n}=387)$ died in hospital. No significant differences were observed in hospital mortality rates between women and men $(2.6 \% v s$. 2.1\%; OR: $1.22,95 \%$ CI: $0.99-1.50)$. The mean age of patients who died was 63 years. For men and women there were statistically significant differences in mortality according to age, with a rise in mortality after the age of 40 . The mortality in cases without an associated physical illness is $0.2 \%(n=12)$ while that in cases with one or more codes of physical disease is $3.7 \%(n=375)$.
Furthermore, cases with schizophrenia as the main discharge diagnosis presented a hospital mortality of $0.3 \%$ ( $\mathrm{n}=27$ cases), whereas that in cases with physical illness in the primary diagnosis was of $6 \%(n=360$ cases). The distribution of the main discharge diagnoses by gender is shown in Table 4 .

To investigate factors associated with in-hospital mortality, we performed an exploratory logistic regression analysis which included gender, age-quartiles, ICD-9 main diagnostic blocks at discharge, and categorized Charlson index scores. The results indicated that the risk of in-hospital death was significantly correlated with age, Charlson index score, and several main ICD-9 codes of physical disease (Table 5). There were no significant interactions between these variables $(p=0.094)$. Moreover, there were no significant differences by gender in mortality after controlling for age, Charlson Index, and ICD categories.

Our study found 387 observed deaths, whereas expected deaths based on general population estimates for the same calendar time amount to 167 [13]. The calculated average SMR is 2.32 (95\%CI: 2.09-2.56). 
Table 3 Frequency of physical diseases in males and females

\begin{tabular}{|c|c|c|c|}
\hline ICD-9-CM groups & Men (\% of cases) & Women (\% of cases) & $\mathrm{OR}^{1}(95 \% \mathrm{Cl}), \mathrm{p}$-value \\
\hline Substance abuse/dependency & 37 & 15 & $3.28(3.02-3.56),<0.001$ \\
\hline Tobacco & 13.8 & 3.9 & $3.9(3.4-4.5),<0.001$ \\
\hline Alcohol & 19 & 5.1 & $4.35(3.9-4.9),<0.001$ \\
\hline Drugs & 18 & 9.9 & $1.9(1.8-2.2),<0.001$ \\
\hline Endocrine, nutritional and metabolic diseases & 13.6 & 22.1 & $0.55(0.51-0.6),<0.001$ \\
\hline Diabetes & 6.3 & 11 & $0.57(0.51-0.64),<0.001$ \\
\hline Diseases of the Circulatory System & 13.2 & 17.4 & $0.7(0.66-0.8),<0.001$ \\
\hline Ischemic heart disease & 2.3 & 1.4 & $1.67(1.3-2.15),<0.001$ \\
\hline Cardiac failure & 1.3 & 1.9 & $0.74(0.58-0.96), 0,019$ \\
\hline Cerebrovascular Disease & 1.2 & 2.2 & $0.54(0.42-0.7),<0.001$ \\
\hline Diseases of the Respiratory System & 12.7 & 11.5 & $1.12(1-1.2), 0.022$ \\
\hline COPD & 6.4 & 3.8 & $1.74(1.5-2.03),<0.001$ \\
\hline Injury-Poisoning & 10.6 & 12.7 & $0.82(0.74-0.91),<0.002$ \\
\hline Diseases of the Digestive System & 10.7 & 9.9 & $1.09(1-1.2), 0.106$ \\
\hline Hepatic & 0.9 & 0.3 & $2.7(1.65-4.42),<0.001$ \\
\hline Diseases of the Nervous System & 7.8 & 9.4 & $0.8(0.73-0.91),<0.001$ \\
\hline Dementia & 0.5 & 1.3 & $0.36(0.26-0.52),<0.001$ \\
\hline Diseases of the Genitourinary System & 5.6 & 9.5 & $0.57(0.5-0.64),<0.001$ \\
\hline Renal Insufficiency & 1 & 1.1 & $0.87(0.64-1.2), 0.39$ \\
\hline Infectious and parasitic diseases & 6.9 & 6.9 & $1(0.88-1.14), 0.99$ \\
\hline AIDS & 1.3 & 0.8 & $1.7(1.23-2.4),<0.001$ \\
\hline Neoplasms & 3.8 & 5.7 & $0.65(0.56-0.75),<0.001$ \\
\hline Diseases of the Blood and blood-forming organs & 3.5 & 5.9 & $0.57(0.49-0.66),<0.001$ \\
\hline Diseases of the Skin and Subcutaneous Tissue & 3.1 & 3.4 & $0.9(0.75-1.08), 0.245$ \\
\hline Diseases of the Musculoskeletal and Connective Tissue & 2.6 & 4.5 & $0.65(0.56-0.75),<0.001$ \\
\hline
\end{tabular}

${ }^{1}$ OR for men versus women. OR: Odds Ratio. Cl: Confidence interval

Table 4 In-hospital deaths: Main discharge diagnosis by gender

\begin{tabular}{llll}
\hline ICD-9-CM main diagnostic categories at discharge & & Number of cases & Women (n= 152) \\
\hline Schizophrenia & Total $(\mathbf{n}=\mathbf{3 8 7})$ & Men $(\mathbf{n}=\mathbf{2 3 5})$ & 6 \\
\hline Physical disease: & 27 & 21 & 37 \\
\hline Diseases of the Circulatory System & 73 & 36 & 26 \\
\hline Diseases of the Respiratory System & 71 & 45 & 22 \\
\hline Neoplasms & 68 & 46 & 22 \\
\hline Injury-Poisoning & 43 & 21 & 14 \\
\hline Diseases of the Digestive System & 36 & 4 \\
\hline Infectious and parasitic diseases & 19 & 15 & 3 \\
\hline Diseases of the Nervous System & 12 & 9 & 3 \\
\hline Endocrine, nutritional and metabolic diseases & 11 & 4 & 1 \\
\hline Diseases of the Genitourinary System & 7 & 4 & 3 \\
\hline Diseases of the Musculoskeletal and Connective Tissue & 5 & 4 & 4 \\
\hline Diseases of the Blood and blood-forming organs & 5 & 2 & \\
\hline Others. Miscellaneous & 10 & 6 & \\
\hline
\end{tabular}


Table 5 Factors related to in-hospital mortality

\begin{tabular}{|c|c|}
\hline & $\operatorname{Exp}(B)(95 \% \mathrm{Cl} \operatorname{Exp} B), p$ value \\
\hline \multicolumn{2}{|l|}{ Gender } \\
\hline Male & Reference group \\
\hline Female & $1.01(0.81-1.27) ; 0.87$ \\
\hline \multicolumn{2}{|l|}{ Age range (quartiles) } \\
\hline $15-31$ years & Reference group \\
\hline $32-40$ years & $1.49(0.76-2.94) ; 0.246$ \\
\hline $41-53$ years & $2.67(1.45-4.91) ; 0.002$ \\
\hline$>53$ years & $6.14(3.40-11.06) ;<0.001$ \\
\hline \multicolumn{2}{|l|}{ ICD-9-CM main diagnostic categories at discharge } \\
\hline Diseases of the Respiratory System & $3.54(2.8-4.48) ;<0.001$ \\
\hline Neoplasms & $2.17(1.52-3.11) ;<0.001$ \\
\hline Diseases of the Circulatory System & $2.16(1.70-2.75) ;<0.001$ \\
\hline Infectious diseases & $1.80(1.36-2.38) ;<0.001$ \\
\hline Diseases of the Digestive System & $1.77(1.39-2.26) ;<0.001$ \\
\hline Injury and Poisoning & $1.57(1.19-2.07) ;<0.001$ \\
\hline Diseases of the Nervous System & $1.45(1.1-1.89) ; 0.007$ \\
\hline \multicolumn{2}{|l|}{ Charlson Index (categorized) } \\
\hline 0 points & Reference group \\
\hline 1-2 points & $1.33(1.01-1.76) ; 0.045$ \\
\hline 3-4 points & $1.76(1.21-2.78) ; 0.01$ \\
\hline$>4$ points & $3.55(2.29-5.52) ;<0.001$ \\
\hline
\end{tabular}

Cl: Confidence interval.

Furthermore, the excess over expected mortality relative to the general population was disproportionately higher in the subgroup of cases with physical disease (Figure 2 ). In fact, the calculated overall SMR in this group of cases is 3.68 (95\%CI: 3.31-4.07).

\section{Discussion}

This study is, to the best of our knowledge, one of the first to provide nationally representative estimates of the prevalence and characteristics of physical disease in hospitalized patients with schizophrenia in Spain. Our results indicate that schizophrenia is associated with a substantial burden of physical comorbidities; that these comorbidities appear early in life; and that they have a severe impact on mortality. Also, in agreement with prior reports $[3,4,19,20]$, our data indicate that hospitalized schizophrenic individuals often have numerous physical diseases, and that several of these diseases are of known clinical severity and prognostic relevance, however, the study design do not allow us for making causal inferences.

As for the most prevalent ICD-9 groups, our data were in general agreement with international figures. Thus, the rates of endocrine, circulatory, respiratory, and digestive diseases in our population were comparable to those in other studies that analyzed whole populations or used administrative data $[19,21,22]$. Certain physical diseases (substance abuse, injury-poisoning, and infections such as AIDS) were much more frequent in young people $[20,23]$. In contrast, circulatory and endocrine diseases were more common in patients over the age of 40 years.

Our data also identify gender-related differences in the physical diseases of patients with schizophrenia. Thus, compared with women, men had significantly higher rates of substance abuse (alcohol, drugs, and cigarettesmoking [24]), and a higher prevalence in certain diagnostic groups, such as chronic respiratory processes, digestive diseases, and infectious diseases $[6,23,25]$. Although men had a lower overall risk of circulatory disease, they suffered more from ischemic heart disease and myocardial infarction. On the other hand, women were more likely to have endocrine diseases, musculoskeletal and connective tissue diseases, neurological diseases, and neoplasms, possibly related to their older age [25-27].

The results of our study add to the existing controversy about differences in the rates of physical illnesses in patients with schizophrenia compared to the general population $[1,7]$. Thus, a comparison of our data and official figures for the Spanish general population 


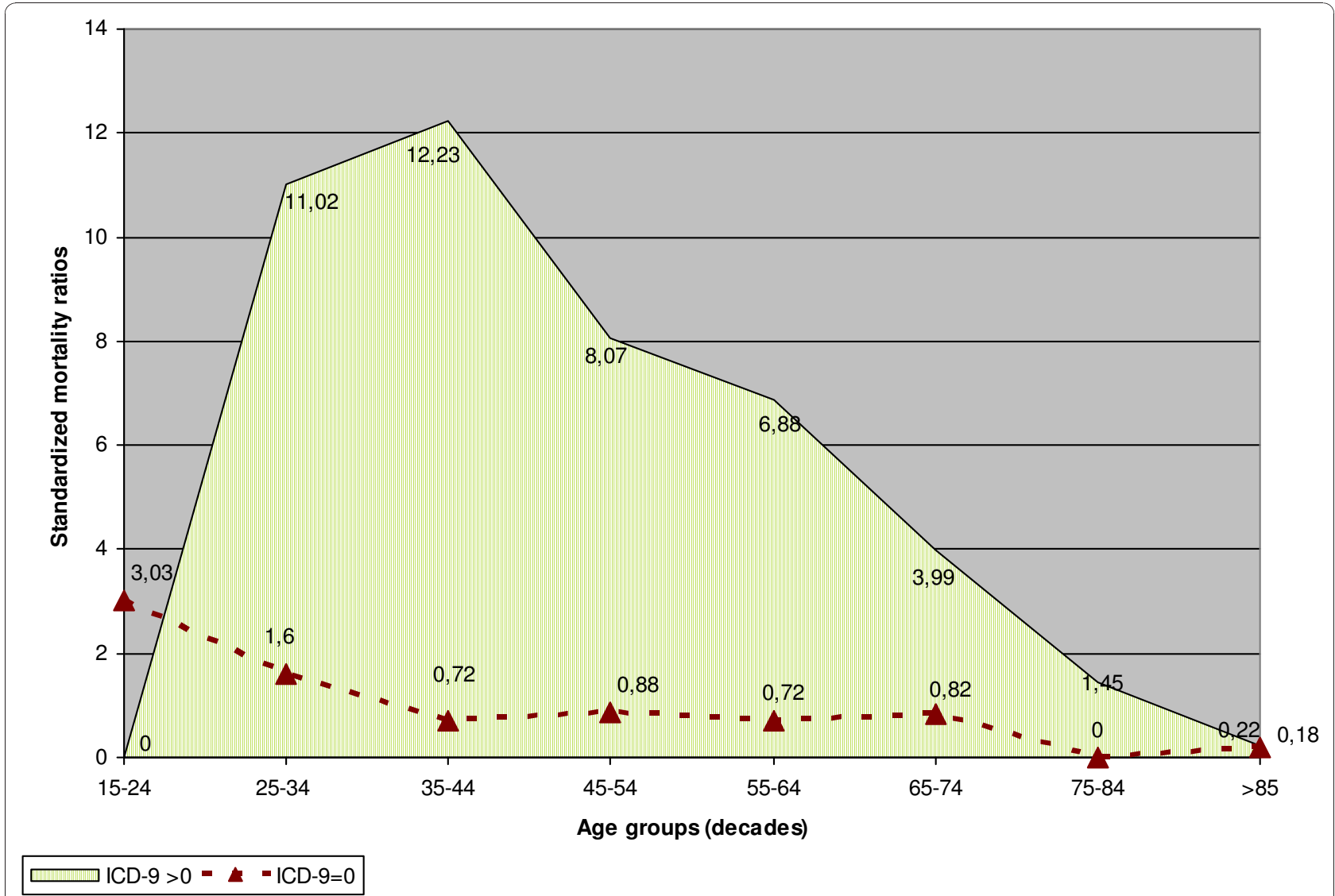

Figure 2 Standardized mortality ratios. Standardized mortality ratios (directly standardized to the 2004 Spanish national population aged $\geq 15$ years) in hospitalized patients with schizophrenia according to 10-year age groups. Data for cases with at least one ICD-9 code of physical disease (filled area); data for cases without ICD-9 codes of physical disease (filled triangles/dotted line).

provided by the National Health Survey [13] suggests that subjects with schizophrenia have higher rates of substance abuse/dependency, diabetes mellitus, digestive diseases, neoplasms, and AIDS. On the other hand, we found no pronounced differences in the frequency of COPD and ischemic heart disease. These findings, though noteworthy in view of the high prevalence of related risk factors, such as diabetes and smoking, are comparable to results of previous studies. Thus, Carney and colleagues [19] found that whereas a somewhat higher percentage of persons with schizophrenia had ischemic heart disease than did controls from the general population $(2.3 \%$ vs. $1.9 \%)$, the adjusted odds ratio was not significant. Regarding COPD, our data also agree with previous reports [25]. However, it should be noted that diagnosis of earlystage COPD can be difficult [28] and the reported rate of COPD may be biased by a failure to perform diagnostic spirometry [29]. In addition, a tendency to ignore a diagnosis of COPD in patients with schizophrenia has been reported [30].
Concerning mortality, this study highlights the impact of physical disease on the risk of death in people with schizophrenia. Our analysis indicates that the Charlson index score and the presence of certain physical diseases (e.g., respiratory, circulatory, tumoral, infectious, digestive, and injury-poisoning) significantly increase the risk of death during hospitalization. In addition, our data underscore that physical disease in schizophrenia was associated to disproportionately high mortality risks relative to the general population. These results, that agree with prior reports [2,31-33], raise concerns about the consequences and causes of physical disorders in patients with schizophrenia and identify a compelling need for a specific approach aimed to detect physical comorbidities, especially those that are most common and closely related to mortality. In this regard, the high risk of mortality from respiratory diseases in our population suggests that a specific approach be used to monitor and control modifiable risk factors, such as smoking [34]. Furthermore, as the prevalence and the type of physical comorbidity show significant differences 
between both genders, the preventive and therapeutic measures to reduce such a disease burden and associated mortality must, in addition, have a specific gender orientation.

Our study was observational, and thus we cannot definitely identify the influence of factors linked to lifestyle, adverse drug effects, or socio-economic level to explain the pattern of physical diseases in our population. Likewise, it is impossible for us to analyze the adequacy of healthcare received by the patients. Several authors have suggested that people with schizophrenia may receive inadequate medical treatment and experience inequalities and difficulties in accessing various medical procedures, even when free and universal healthcare is available, as in Spain, at the point of care $[35,36]$.

The results of this study extend previous work by providing a comprehensive overview of medical disorders associated with schizophrenia. In particular, our study has several strengths compared to previous reports: (a) we characterized physical diseases in a large populationbased representative sample of patients with schizophrenia; and, (b) we included all diseases and objectively classified them according to the ICD-9 system. In addition, our data represent clinical practice patterns for professionals nationwide, allowing us to generalize the results. Furthermore, the use of the Charlson comorbidity index, which is widely used to predict hospitalization outcome, increases the validity of observations.

We must also acknowledge possible limitations of our work. This study is subject to the limitations inherent in retrospective studies using administrative databases. Data from these databases lack of many measures obtainable only from chart review or survey with the attendant potential for omitting important prognostic factors. Furthermore, these data do not allow causal inferences to be made. However, the use of such databases is well-established in psychiatric epidemiology and health services research and has been shown to furnish valuable information for assessing the need for preventive and therapeutic care and for service planning [37-39]. Additionally, the Spanish Ministry of Health [12] systematically performs assurance audits of the National Hospital Discharge Registry to verify coding adequacy. Moreover, we followed the guidelines for reporting observational studies, as outlined by the STROBE Initiative [40].

We also recognize that the presence of a control group would have resulted in more far-reaching results and a more precise determination of the risk and time of development of physical comorbidities in patients with schizophrenia. Currently, however, it was not possible for us to consider a sufficiently large control group representative of the patients studied. Nevertheless, given that, to our knowledge, this work constitutes the first study with this range of diagnosis and population size carried out in our country, we hope that our results will be the base of other studies with a stronger methodological design.

Finally, it is inarguable that hospitalized subjects will have a disease load and severity greater than the outpatient population. However, our results clearly show the distribution and prevalence of different physical diseases that can contribute to the deterioration of health, causing patients to be admitted into hospital and increasing their risk of death. As with several recent studies $[36,41]$, our results have implications for the design of preventive and therapeutic programs and services for people with schizophrenia that aim to reduce the prevalence and negative impacts of physical diseases in this population.

\section{Conclusions}

In summary, we analyzed a nationwide database to determine the prevalence and characteristics of physical diseases in hospitalized patients with schizophrenia. Our results indicate that physical illness is a major burden for such patients, that these comorbidities appear early in life and that they have a serious impact on mortality. This information raises concerns about the consequences and causes of physical disorders in patients with schizophrenia and may prove useful in the design and implementation of preventive and therapeutic programs and for health-care service planning.

\section{Acknowledgements}

Funding for this study was provided by the Spanish R\&D Grant no. PI06/ 90571. The funding body had no further role in study design, data collection, analysis, interpretation, writing of the report, or the decision to submit the paper for publication.

\section{Author details}

${ }^{1}$ Health-Care Technology Assessment Agency, Instituto de Salud Carlos III, Madrid, Spain. ${ }^{2}$ National Epidemiology Centre, Instituto de Salud Carlos III, Madrid, Spain.

\section{Authors' contributions}

Authors CB and JM Amate designed the study, wrote the protocol, and managed literature searches and analysis. Authors CB and TL performed the statistical analysis. Author CB wrote the first draft of the manuscript. All authors contributed to and have approved the final manuscript.

Competing interests

The authors declare that they have no competing interests.

Received: 10 December 2009 Accepted: 2 December 2010

Published: 2 December 2010

\section{References}

1. Jeste DV, Gladsjo JA, Lindamer LA, Lacro JP: Medical comorbidity in schizophrenia. Schizophr Bull 1996, 22:413-430

2. Brown S: Excess mortality of schizophrenia. A meta-analysis. $\mathrm{Br} \mathrm{J}$ Psychiatry 1997, 171:502-508.

3. Goldman LS: Medical illness in patients with schizophrenia. J Clin Psychiatry 1999, 60(Suppl 21):10-15 
4. Dixon L, Postrado L, Delahanty J, Fischer PJ, Lehman A: The association of medical comorbidity in schizophrenia with poor physical and mental health. J Nerv Ment Dis 1999, 187:496-502.

5. Chwastiak LA, Rosenheck RA, McEvoy JP, Keefe RS, Swartz MS, Lieberman JA: Interrelationships of psychiatric symptom severity, medical comorbidity, and functioning in schizophrenia. Psychiatr Serv 2006, 57:1102-1109.

6. Green Al, Canuso CM, Brenner MJ, Wojcik JD: Detection and management of comorbidity in patients with schizophrenia. Psychiatr Clin North Am 2003, 26:115-139.

7. Leucht S, Burkard T, Henderson J, Maj M, Sartorius N: Physical illness and schizophrenia: a review of the literature. Acta Psychiatr Scand 2007, 116:317-333.

8. Salokangas RK: Medical problems in schizophrenia patients living in the community (alternative facilities). Curr Opin Psychiatry 2007, 20:402-405.

9. Garcia J, Vázquez-Barquero J: Deinstitutionalization and psychiatric reform in Spain. Actas Esp Psiquiatr 1999, 27:281-291.

10. Vázquez-Barquero JL, García J, Torres-González F: Spanish psychiatric reform: what can be learned from two decades of experience? Acta Psychiatr Scand Suppl 2001, 410:89-95.

11. Salvador-Carulla L, Tibaldi G, Johnson S, Scala E, Romero C, Munizza C, (for the CSRP/RIRAG groups): Patterns of mental health service utilization in Italy and Spain: An investigation using the European Service Mapping Schedule. Soc Psychiatry Psychiatr Epidemiol 2005, 40:149-159.

12. Ministerio de Sanidad y Politica Social: Sistema de Información Sanitaria Servicio Nacional de Salud.[http://www.msc.es/en/estadEstudios/ estadisticas/sisInfSanSNS/home.htm]

13. Instituto Nacional de Estadística:[http://www.ine.es]

14. Dickey B, Normand SLT, Weiss RD, Drake RE, Azeni H: Medical morbidity, mental illness, and substance use disorders. Psychiatr Serv 2002, 53:861-867.

15. Deyo RA, Cherkin DC, Ciol MA: Adapting a clinical comorbidity index for use with ICD-9-CM administrative databases. J Clin Epidemiol 1992, 45:613-619.

16. Charlson ME, Pompei $P$, Ales $K L$, Mackenzie CR: A new method of classifying prognostic comorbidity in longitudinal studies: development and validation. J Chron Dis 1987, 40:373-383.

17. Librero J, Peiró S, Ordiñana R: Chronic comorbidity and outcomes of hospital care: length of stay, mortality and readmission at 30 and 365 days. J Clin Epidemiol 1999, 52:171-179.

18. Estève J, Benhamou E, Raymond L: Méthodes statistiques en épidémiologie descriptive Paris: Les éditions INSERM; 1993.

19. Carney CP, Jones L, Woolson RF: Medical comorbidity in women and men with schizophrenia: a population-based controlled study. J Gen Intern Med 2006, 21:1133-1137.

20. Kilbourne AM, Cornelius JR, Han X, Haas GL, Salloum I, Conigliaro J, Pincus HA: General-medical conditions in older patients with serious mental illness. Am J Geriatr Psychiatry 2005, 13:250-254.

21. Daumit GL, Pronovost PJ, Anthony CB, Guallar E, Steinwachs DM, Ford DE: Adverse events during medical and surgical hospitalizations for persons with schizophrenia. Arch Gen Psychiatry 2006, 63:267-272.

22. Ringen $P$. Melle I, Birkenaes $A B$, Engh JA, Faerden $A$, Jónsdóttir $H$, Nesvåg $R$, Vaskinn A, Friis S, Larsen F, Opjordsmoen S, Sundet K, Andreassen OA: Illicit drug use in patients with psycotic disorders compared with that in the general population: a cross-sectional study. Acta Psychiatr Scand 2008, 117:133-138.

23. Cournos F, McKinnon K, Sullivan G: Schizophrenia and comorbid human immunodeficiency virus or hepatitis C virus. J Clin Psychiatry 2005, 66(Suppl 6):27-33.

24. Lindamer LA, Bailey A, Hawthorne W, Folsom DP, Gilmer TP, Garcia P, Hough RL, Jeste DV: Gender differences in characteristics and service use of public mental health patients with schizophrenia. Psychiat Serv 2003, 54:1407-1409.

25. Mäkikyrö T, Karvonen JT, Hakko H, Nieminen P, Joukamaa M, Isohanni M, Jones $P$, Järvelin MR: Comorbidity of hospital-treated psychiatric and physical disorders with special reference to schizophrenia: a 28 year follow-up of the 1966 northern Finland general population birth cohort. Public Health 1998, 112:221-228.

26. Gulbinat W, Dupont A, Jablensky A, Jensen OM, Marsella A, Nakane Y, Sartorius N: Cancer incidence of schizophrenic patients. Results of record linkage studies in three countries. Br J Psychiatry Supp/ 1992, 18:75-83.
27. Dixon L, Weiden P, Delahanty J, Goldberg R, Postrado L, Lucksted A, Lehman A: Prevalence and correlates of diabetes in national schizophrenia samples. Schizophr Bull 2000, 26:903-912.

28. Filik R, Sipos A, Kehoe PG, Burns T, Cooper SJ, Stevens H, Laugharne R, Young G, Perrington S, McKendrick J, Stephenson D, Harrison G: The cardiovascular and respiratory health of people with schizophrenia. Acta Psychiatr Scand 2006, 113:298-305.

29. Himelhoch S, Lehman A, Kreyenbuhl J, Daumit G, Brown C, Dixon L: Prevalence of chronic obstructive pulmonary disease among those with serious mental illness. Am J Psychiatry 2004, 161:2317-2319.

30. Cradock-O'Leary J, Young AS, Yano EM, Wang M, Lee ML: Use of general medical services by VA patients with psychiatric disorders. Psychiatr Serv 2002, 53:874-878.

31. Osby U, Correia N, Brandt L, Ekbom A, Sparen P: Time trends in schizophrenia mortality in Stockholm County, Sweden: cohort study. $\mathrm{Br}$ Med J 2000, 321:483-484.

32. Enger C, Weatherby L, Reynolds RF, Glasser DB, Walker AM: Serious cardiovascular events and mortality among patients with schizophrenia. J Nerv Ment Dis 2004, 192:19-27.

33. Saha $S$, Chant D, McGrath J: A systematic review of mortality in schizophrenia. Is the differential mortality gap worsening over time? Arch Gen Psychiatry 2007, 64:1123-1131.

34. Mitchell AJ, Malone D: Physical health and Schizophrenia. Curr Opin Psychiatry 2006, 19:432-437.

35. Kisely S, Smith M, Lawrence D, Cox M, Campbell LA, Maaten S: Inequitable access for mentally ill patients to some medically necessary procedures. CMAJ 2007, 176:779-784.

36. Fleischhacker WW, Cetkovich-Bakmas M, De Hert M, Hennekens CH, Lambert M, Leucht S, Maj M, McIntyre RS, Naber D, Newcomer JW, Olfson M, Osby U, Sartorius N, Lieberman JA: Comorbid somatic illnesses in patients with severe mental disorders: clinical, policy, and research challenges. J Clin Psychiatry 2008, 69:514-519.

37. Lawrenson R, Williams T, Farmer R: Clinical information for research: the use of general practice databases. J Public Health Med 1999, 21:299-304.

38. Nazareth I, King M, Haines A, Rangel L, Myers S: Accuracy of diagnosis of psychosis on general practice computer system. Br Med J 1993, 307:32-34.

39. Byrne $N$, Regan C, Howard L: Administrative registers in psychiatric research: a systematic review of validity studies. Acta Psychiatr Scand 2005, 112:409-414.

40. von Elm E, Altman DG, Egger M, Pocock SJ, Gøtzsche PC, Vandenbroucke JP, STROBE Initiative: The Strengthening the Reporting of Observational Studies in Epidemiology (STROBE) statement: guidelines for reporting observational studies. Bull World Health Organ 2007, 85:867-872.

41. Kane JM: Creating a health care team to manage chronic medical illnesses in patients with severe mental illness: The public policy perspective. J Clin Psychiatry 2009, 70(Suppl 3):37-42.

\section{Pre-publication history}

The pre-publication history for this paper can be accessed here: http://www.biomedcentral.com/1471-2458/10/745/prepub

doi:10.1186/1471-2458-10-745

Cite this article as: Bouza et al:: Physical disease in schizophrenia: a population-based analysis in Spain. BMC Public Health 2010 10:745. 